\title{
Ultimate justification: Wittgenstein and medical ethics
}

\author{
Julian Hughes Princess Alexandra's Royal Air Force Hospital, Wroughton
}

\begin{abstract}
Decisions must be justified. In medical ethics various grounds are given to justify decisions, but ultimate justification seems illusory and little considered. The philosopher Wittgenstein discusses the problem of ultimate justification in the context of general philosophy. His comments, nevertheless, are pertinent to ethics. From a discussion of Wittgensteinian notions, such as 'bedrock', the idea that 'ultimate' justification is grounded in human nature as such is derived. This discussion is relevant to medical ethics in at least five ways: it shows generally what type of certainty there is in practical ethics; it seems to imply some objective foundation to our ethical judgements; it squares with our experience of making ethical decisions; it shows something of the nature of moral arguments; and, finally, it has implications for teaching medicine and ethics.
\end{abstract}

\section{Introduction}

In writing, ' $\ldots$ the problem of ultimate justification is no more of a problem for utilitarianism (and no less) than it is for any other moral theory', Raanan Gillon (1) acknowledges a problem which, actually, is not often faced in moral philosophy or elsewhere. Perhaps, although this would be philosophical cowardice, the 'problem of ultimate justification' is too daunting. But, surely, 'critical evaluation of assumptions and arguments' (2) must lead us to look at ultimate justification.

It is important not to overlook the force of the adjective ultimate, for sceptical doubt drives us to 'the limits of justification and beyond' (3). Now, one reaction to sceptical questionings is a philosophical stamp of the foot, like Phillips (4) saying (in another context), 'Sometimes, the insistence on asking further questions is not a sign of commendable intellectual persistence, but of stubbornness and stupidity; a failure to recognize when enough is enough'.

\section{Key words}

Wittgenstein; ultimate justification; philosophical ethics; objectivity in ethics; natural moral law.
In this paper I shall discuss the problem of ultimate justification. Clearly, it is unlikely that the problem will be dealt with in a manner sufficient to satisfy a professional philosopher as it is entangled in a morass of wider philosophical problems. A broader philosophical view, which has certainly helped to clarify some of my thoughts, may be found in Paul Johnston's Wittgenstein and Moral Philosophy (5). Any illumination given here is likely to be that of a spark rather than of a torch. My intention is to raise the issue of ultimate justification in the context of medical ethics and to suggest it sheds light on 'assumptions and arguments' which govern our decisions and actions.

\section{The problem}

To 'justify' means to 'adduce adequate grounds' (6). In medicine we frequently must give grounds for our action to patients or to colleagues. Infrequently we may have to justify our actions in open court. Daily, meanwhile, we acquire facility at giving grounds to ourselves for our decisions. It becomes easy to justify withholding antibiotics from an elderly stroke victim with pneumonia, or to justify sterilising a woman whose social circumstances or intelligence are poor, or to justify breaking confidentiality one day and withholding a diagnosis from a patient the next. I mean we can adduce grounds for these actions and with sophistication we can point to a respect for autonomy, beneficence, non-maleficence and justice (7).

However, in each case the grounds can be questioned. We do this by pointing out that whilst here we seem to have respected autonomy, elsewhere autonomy appears to have been disregarded; or, by arguing about just what does count as respect for autonomy, or about where autonomy is to be respected. But then, we can question the grounds for respecting autonomy at all: indeed, is there, since it is clearly not an absolute thing, any ultimate justification for it?

We could simply say, 'enough is enough', that some things are self-evidently right. It is not selfevidently true, however, that we should not ask our question, which raises the problem of ultimate 
justification. For if there is no ultimate justification then every justification seems arbitrary. Then, your justification for euthanasia will always seem as valid as my justification for condemning it, irrespective of how well or badly it has been put. The justification and its rejection both float without grounds. The consequence of this is the feeling that in medical ethics there cannot be right or wrong answers. Its corollary is another feeling, that medical ethics does not much matter. Thus, one consultant gives intravenous fluids to the unconscious major stroke victim whilst another does not, and house officers moving from one firm to the other simply do their bidding.

\section{Wittgenstein and ultimate justification}

The problem of ultimate justification is discussed by the philosopher, Ludwig Wittgenstein. His comments come in various contexts, such as in discussions of notions like 'following a rule'. A full account of Wittgenstein on justification would involve consideration of problems of meaning and the philosophy of language, which is beyond our scope, but this does not make his specific comments irrelevant to, nor abstruse for, our purposes.

Wittgenstein makes the point several times that the process of justification must come to an end in order for it to be a justification $(8,9)$. Given that actions are, in practice, justified, they cannot be justified by a justification which itself needs justifying. Making the same point differently he says, 'If the true is what is grounded, then the ground is not true, nor yet false' (10). What, then, is it that lies at the bottom of justification? What is the ground which is itself neither true nor false?

In his discussion in Philosophical Investigations (11) of following a rule he states that the question 'is about the justification for my following the rule in the way I do'. He continues: 'If I have exhausted the justifications I have reached bedrock, and my spade is turned. Then I am inclined to say: "This is simply what I do"'.

In On Certainty (12) he says, 'Giving grounds ... justifying the evidence, comes to an end; - but the end is not certain propositions' striking us immediately as true, ie, it is not a kind of seeing on our part; it is our acting, which lies at the bottom of the language-game'. Johnston (13) puts it thus: '... in understanding human action one eventually reaches the bedrock of a reaction, for at some point the giving of reasons comes to an end, and we are faced with the fact that the individual acted as he did'. Again, Wittgenstein (14) says that the end of giving grounds is not an ungrounded presupposition: it is an ungrounded way of acting'. In the same work (15) he describes something beyond being justified or unjustified as being 'something animal'.

For Wittgenstein the way in which the notion of justification arises in different contexts reveals what he describes as a 'language-game'. Further, aळ language-game reflects a 'form of life' (16) and as such cannot be justified (17). He says, 'What has tof be accepted, the given, is - so one could say - forms of life' (18). Thus 'ultimate justification' lies in: 'something animal', 'the given', or a 'form of life'. I is 'simply what I do'. Wittgenstein (19) sayso elsewhere, "What people accept as justification - is shewn by how they think and live'.

In fact, Wittgenstein's work includes more specific mention of ethics. The Lecture on Ethics is at pains ton delineate between ethical and other types of discourse. Thus, 'no statement of fact can ever be, or? imply, a judgement of absolute value' (20). Ethics is precisely to do with judgements of absolute value which by their nature cannot be verified empirically as true or false. As Johnston (21) summarises: 'It is misleading to note that moral judgements are not supported by evidence and then to treat this as weakness. Such a claim assimilates moral judgements to unsubstantiated empirical claims ... they belong to음 a different category from empirical judgements and hence have a completely different grammar'.

Much more could be said about the ideas contained in the Lecture (22). What is just as intriguing is the feeling that much else that Wittgenstein wrote is relevant to ethics even whent? apparently more concerned with, say, logice. Wittgenstein is, indeed, quoted as saying that Tractatus Logico-Philosophicus 'was really a bogi about ethics' (23).

The quotations already given illustrate the connection between notions such as 'following rule' and 'forms of life', in which justifications $\overrightarrow{\vec{F}}$ shown by how people 'think and live', are grounded 3 To such considerations we now return to ask what relevance they have to practical ethics. I shall discussof. five ways in which Wittgenstein's comments, made in relation to the philosophy of language, grammaro and logic, are so relevant.

\section{The grounds of ethics}

Well, first, Wittgenstein's comments are relevant inf themselves because they throw light on the problem of ultimate justification and raise a question concerning the grounds for ethical judgements. Noț surprisingly, there is no uniform exegesis of Wittgenstein's views. For instance, in a controversiab interpretation Kripke (24) stressed the sceptical nature of Wittgenstein's enquiry and suggested tha the solution to the problem (he was considering the problem of the ultimate justification of meaning one्ष thing rather than another by a particular utterance of resided in the community's use of words and meanings. On the other hand, Baker and Hacker $3 \frac{8}{\circ}$ have roundly condemned this interpretation of Wittgenstein, whom they say argues precisely agains sceptical doubt, showing it to be senseless. Fog them, what Wittgenstein achieves is a rebuttal of the 
reasonableness of doubting at the point of ultimate justification: therefore, the problem of ultimate justification is chimerical. Hence, 'Absence of grounds is a criticism if grounds are at least possible, and if doubt about justification is reasonable. But neither of these conditions obtains here, where justifications terminate' (25).

Pursuing the debate between these interpretations fully, although beyond our scope, is apposite, I believe, to problems in medical ethics. It will reveal something about what counts as adequate grounds in general and, therefore, the type of certainty which we can hope for in practical philosophy.

\section{Bedrock and objective foundations}

There is a second way in which Wittgenstein's comments are relevant to ethics. The point at which seeking justifications comes to an end is, for Wittgenstein, an action. Specifically, it is my action: 'This is simply what I do'. One possible, rather literal, interpretation of this is that ethics is highly subjective, that my personal preference is ultimately what counts. It would be strange, however, in discussing meaning, if Wittgenstein were happy to say that we can all feasibly mean whatever we like by a given term. There must be, we might assume, as Kripke argued, at least community agreement. Transposed to ethics, this suggests (at first blush) that the ultimate justification of an action resides in community agreement. Nevertheless it does raise further problems. Essentially, it raises the original problem at another level: how do we justify siding with community $A$ which, say, rejects infanticide rather than community $B$ which accepts it?

Further, there is the considerable doubt that Wittgenstein intended anything like this, either in language or ethics. Baker and Hacker (26) have persuasively argued that Wittgenstein's point 'is not that rule-following and language are necessarily social but that they are necessarily public'. Wittgenstein is discussing the grammar of notions such as rule-following, which entails that a practice of rule-following must be in principle public. But, 'the grammatical point involves no reference to society' (27). Whether others are involved in this practice is, as Baker and Hacker (28) suggest, 'a further question'.

Wittgenstein speaks of 'something animal' and 'the given'. Elsewhere he mentions, that which is understood before any particular language, 'the common behaviour of mankind' (29). Now this sounds as if what we are being grounded in is not a particular community but the whole of 'mankind'. Let us, pace Wittgenstein, follow this argument freely.

'This is simply what I do' does not mean I can do whatever I want. But, what I do reflects what I am and what I am at root is a human being living in a world of human beings. What I am personally may, of course, be brutish; but it could be suggested that being human as opposed to being a brute entails that there is something about being human qua human which should prescribe and proscribe our behaviour.

So, we are shown what we must really study to make headway in ethics: human beings as such. But is that so original or profound? Well it is easily overlooked. Our vision is too frequently finely focused on particulars. Detailed argument about particular instances is necessary, but the ultimate justification for a particular decision in medical ethics is grounded in the actions of human beings as such. This overview (to cadge another Wittgensteinian notion) promotes profundity by prohibiting glib or facile answers.

There is another sense in which it is unoriginal to argue that the problem of ultimate justification forces us back to actions as they are specifically human. For instance, it might be that 'my spade is turned' and I reach bedrock at a moral precept such as 'Good is to be sought and evil avoided'. This, then, would be part of 'the given' and of a general 'form of life'. Such a moral precept would be a part of the woof and warp of human existence. It is a short step to talk, then, of a natural moral order. Insistence on a natural moral order, shown by our moral stances and actions, has a long lineage. It will not be palatable to many and must be made tentatively. Nevertheless, if we are admonished to seek ultimate justification in how people 'think and live', to look at 'the given' and what people actually do, at the choices they make and their inclinations and wishes, then it sounds as though the possibility of a natural moral order has been countenanced.

What must be avoided, however, is any tendency to slip into a way of speaking which makes it appear that we have accepted 'the good' as being some sort of 'thing', - an example of the 'bewitchment of our intelligence by means of language' (30). Wittgenstein says, 'You cannot lead people to what is good; you can only lead them to some place or other. The good is outside the space of facts' (31). Still, wishing always 'to seek the good' may be a reasonable description of our actions, and of the actions of humans generally, and not the sort of grounds that can admit of further justification. The intelligibility of the statement will depend on how it is used and the function it plays in the lives of those who use it.

I have suggested, then, that the second way in which we may use Wittgenstein's comments is to take the notion of 'bedrock' as implying some objective foundation to our ethical judgements. I have extended this to say that the bedrock may actually be common - 'the common behaviour of mankind' - revealing what in the past has been called a natural moral order. If this is not overtly in Wittgenstein, at least the possibility of objective moral values and the incoherence of subjectivism in ethics seem implicit. 'Objectivity' is not in terms of a correspondence with facts. 'Rather, in this context 
the claim to truth or objectivity expresses the claim that one set of judgements about how people should act is uniquely correct and that the standards embodied in these judgements ought to be recognized by everyone just because this is so' (32). Alternatively, subjectivism would involve a person in the substantive claim that moral disagreements were simply disputes over matters of taste. Wittgenstein's discussion suggests that '.. disagreement is not merely verbal but very real - it reflects the conflict between two ways of understanding the world and correspondingly two different ways of acting' (33). Subjectivism seems to miss the point about ethics: that matters of taste are in no way equivalent to matters of absolute value. Rush Rhees (34) uses the example of a man playing tennis badly who might say 'I don't want to play any better', which might reasonably be accepted. But where someone has behaved badly it would not make sense to accept a similar excuse, 'I don't want to behave any better', because a person ought to want to behave better.

\section{The argument from experience}

Thirdly, to revert to the relevance of our comments from Wittgenstein to medical ethics, it could be argued that Wittgenstein's account of justification is more realistic than pictures often presented by ethical theories. His account squares with our experience of ethical decisions and thereby narrows the spectre of a chasm between armchair philosophy and practical decisions, which have to be made on our feet!

A fifteen-year-old girl comes to see me seeking termination of her pregnancy but does not want her parents informed. In deciding what is morally correct, do I feel as if I apply a felicific calculus to maximize happiness? Do I quickly think of autonomy, justice, beneficence and non-maleficence? I would suggest that what it actually feels like is that I just act: 'This is simply what I do'.

Now, clearly, I can be accused of misunderstanding the philosophical point: 'critical evaluation' may occur later, should have occurred sooner, but whenever it occurs, may well require utilitarian and other notions. I question, however, whether this textbook type of ratiocination usually, if ever, occurs in the real world. Of course, it can. We can persuade ourselves that by telling (or not telling) her parents we were acting with justice and non-maleficence, or some other concoction of the preferred formulation. Does this, however, really satisfy our craving for ultimate justification? To make the point in a pseudoanti-intellectual way, the textbook may proffer a justification to satisfy 'the head', but what of 'the heart'? At root, I am satisfied that my action is right if it is in accord with my deep-seated instincts, if it squares with my general perception of human needs and wants. And my action will have sprung from these instincts and perceptions, even intuitions; in short, from 'something animal'.
Even if we do use 'textbook' justificatory arguments, if they satisfy us it is likely to be because $\mathrm{m}$ they are in accord with an underlying reality ('the $\overrightarrow{\bar{E}}$. given') about human beings as such. So my point is not anti-intellectual; it is rather the demand that we should dig deeper until the spade is turned. But it is also the suggestion that the most vital criticalo evaluation to take place is that which measures this $\frac{\bar{D}}{\bar{N}}$ particular action against my other actions and $\frac{\bar{c}}{\bar{\sigma}}$ beliefs.

Wittgenstein (35) similarly writes: 'Nothing we do can be defended absolutely and finally. But only by reference to something else that is not questioned. Ie, no reason can be given why you should act (or $\vec{\omega}$ should have acted) like this, except that by doing so you bring about such and such a situation, which again has to be an aim you accept'. Several points arise from this quotation. Wittgenstein implies that. the absolute defence of an action comes from its $\vec{\sim}$ relationship to another action which is just accepted. ON His thrust is that there must be something which is ? not questioned. This bedrock would provide the $\overrightarrow{-}$ basis for absolutes in ethics.

Now, this links with the point I am making at present, that the notion of checking our actions against our other actions and beliefs is much more like what we really do in practical philosophy. These $\mathbb{E}$ 'other actions and beliefs' have to be things whishs. are not questioned. Or, if they are, they are likely be held in place by further unquestioned actions afy beliefs, so that the whole complex of actions ard beliefs may acquire a self-supporting nature (which is only intended as a metaphor). My particular $\stackrel{\square}{\square}$ complex reflects and constitutes my particular $\overrightarrow{\vec{B}}$ nature, which may be vicious or virtuous.

Moreover, it is from this nature that my actions? emanate. I am aware of nothing but that when I reply무. to the fifteen-year-old girl, not of ratiocinations usually described in philosophical medical ethics. This awareness is by no means irrelevant to a true understanding of medical ethics. This is not, it must be emphasized, an argument against criticalo evaluation, but it is an argument from experience. As Johnston (36) says: '... the basis of moral belief is not음 specific evidence but ... the entirety of the $>$ individual's experience'. Or again (37), if one's viewpoint is grounded in anything it is in 'all the N individual has seen, thought, and experienced'. This description more readily squares with the experience 0 of making decisions of a moral nature.

\section{Moral arguments}

The fourth way in which Wittgensteinian notions are $\stackrel{\mathbb{P}}{+}$ relevant to medical ethics concerns moral arguments. In disagreements we point out to our opponents things which they accept but which are at $\stackrel{\mathbb{P}}{\stackrel{P}{Q}}$ odds with the thing in question. We, as it were, point $\stackrel{\mathbb{Q}}{\mathscr{Q}}$ out irregularities in their particular systems of beliefs. In arguments the presupposition is that 
irregularities should be made regular, that the systems of beliefs should even come to resemble, more or less, each other.

The corollary would then be that there exists, in theory, a perfect system of beliefs, a perfect complex, shown in our human natures, if we could but hone it down by frank argument and honest evaluation. This may amount to no more than persuasion to look at things in a particular way; like Wittgenstein (38) saying: 'At the end of reasons comes persuasion'. Ethical arguments need not be taken any less seriously if we candidly accept that at root they are a matter of persuasion; the strength of our belief in our world view determines our seriousness.

Johnston (39) highlights that whilst moral discussion is possible the notion of bedrock means that it may end in irresolvable disagreement. Again, this $i s$ the experience of arguments in medical ethics, abortion being an obvious example. New facts do not seem to help much. The irresolvable nature of the disputes stems from the nature of ethical beliefs. Nevertheless, cases may be compared to look for morally relevant differences. For it remains important that there is consistency in ethics and it is in inconsistency that persuasion may gain a purchase. Accepting that there may be irresolvable disagreements does not commit us to subjectivism; if anything, it stems from a recognition of the nature of moral judgements qua judgements, as opposed to mere dispositions or preferences which lack the feeling of immutability required for a thing to have a specifically moral character.

Given that moral arguments are grounded in the human being as such it follows that anything pertaining to the human being might well be relevant in these arguments: 'anything that one person can tell another which will lead him to change his way of seeing the world or alter his sense of right and wrong constitutes a possible form of a moral argument' (36). To be candid, persuasion may take a number of forms but these must, for the sake of consistency, be within the bounds of the morality being advocated. This thought, that someone could be 'unethically' persuaded (tortured, brainwashed) to accept an 'ethical' creed brings to mind Wittgenstein's comment recorded by Rush Rhees (40) on Goering's 'Recht ist das, was uns gefällt' ('Right is whatever we want it to be'): '... even that is a kind of ethics. It is helpful in silencing objections to a certain attitude. And it should be considered along with other ethical judgements and discussions, in the anthropological study of ethical discussions which we may have to conduct'.

This re-emphasizes the purpose of Wittgenstein's philosophy, namely to give some sort of clarity to avoid conceptual confusion. His point is to show the special nature of ethical considerations which make substantive claims, not empirical or logical claims.

It may well be that Johnston and Wittgenstein would be inimical to talk of 'the human being as such'. Perhaps all we can actually refer to are particular people with particular histories and world views. Yet $I$ am suggesting two more points which may be equally contentious.

First, to hold an ethical view in the sense elucidated by Johnston, with its substantive claim to objectivity, seems to suggest something common to mankind (like the 'common behaviour of mankind'), which amounts to a natural moral order. We argue so vehemently because of a 'perception' of the right way - although it is not a perception of a particular entity or fact, rather of 'the given', 'something animal', but virtuous not vicious. At root, accepting that there is a natural moral order is a substantive ethical judgement. It cannot be given, nor does it require, further justification. Like Wittgenstein at the end of the Lecture on Ethics I can only speak in the first person. I find that such a judgement 'makes sense', which means that it accords with my Weltanschauung - 'This is simply what I do'.

Secondly, Johnston (41) is critical of a view suggested by Hurley which appears to suggest that, '.. unbeknownst to the individual, he may believe that a certain act is wrong', which Johnston feels would be 'highly paradoxical'. However, when I try to persuade someone to change a particular ethical view it might well seem that she knows the view is wrong - or should do, by looking at the rest of her proceedings - even though she cannot yet see it herself. If I did not have this feeling, perhaps, the argument would be utterly hopeless and pointless. I recognise that my opponent may have the same conviction, but that is not something I can help: she is simply mistaken. To deny this sense of certainty might seem less awkward, but would also be to deny the special character of our ethical beliefs which should include, after all, a morally acceptable way of dealing with those with whom we cannot agree.

\section{Teaching medicine and ethics}

Regarding ethical arguments in this light has implications for teaching medicine, which is a final reason why Wittgenstein's comments have a bearing on medical ethics. For one thing, if medical ethics is mainly concerned with human beings as such, then doctors require as wide an understanding of human nature as possible. This will not be provided best by specialising solely in the sciences, no matter how important these are, but will be aided by studying the humanities.

Moreover, medical ethics is not just a matter of learning different ethical theories, like learning more facts or a new language. On the view expressed here it is certainly not about accepting different opinions as being equally valid as one's own. It is about having and holding a worldview and trying to persuade others to see the world in our way, whilst acknowledging the similarly strongly held views of our opponents. This acknowledgement is a matter 
both of courtesy and of practical wisdom; we refine our views by exposure to the world. Our views may change. This is not precluded, since the notion of ethics advocated entails that someone is wrong. At least, by public scrutiny of our views, we may achieve more clarity.

Teaching medical ethics becomes a process of clarification, not just one of sophistication for previously glibly held views. Medical ethics should provide an overview of the full implications of any particular medical decision for how we 'think and live'. This extends even to our attitude towards the patient as a human being. I think it explains Wittgenstein's advice to his former pupil and friend Drury (42), who felt inadequate as a newly qualified doctor: 'Look at your patients more closely as human beings in trouble and enjoy more the opportunity you have to say "good night" to so many people. This alone is a gift from heaven which many people would envy you ... I think in some sense you don't look at people's faces closely enough'.

\section{Acknowledgements}

I am grateful to the referees of the fournal of Medical Ethics whose useful criticisms have substantially improved this paper. I am also grateful to Air Commodore H A Wober (formerly Principal Medical Officer, RAF Germany) and to Anne Hughes for useful textual comments: remaining inadequacies are entirely my responsibility. Mrs Susan Ley willingly typed an earlier draft and her help is acknowledged with thanks.

\section{Disclaimer}

The views expressed in this article are entirely personal and not to be considered as representing the opinions of the Royal Air Force Medical Services.

Fulian Hughes, $M A, M B, C h B, A L C M, R A F$ is a Registrar in Psychiatry at Princess Alexandra's RAF Hospital Wroughton, previously having trained in General Practice.

\section{References}

(1) Gillon R. Philosophical medical ethics. Chichester: John Wiley \& Sons, 1986: 25.
(2) Raphael D D. Moral philosophy. Oxford: Oxfor University Press, 1981: 1.

(3) Baker G P, Hacker P M S. Scepticism, rules an language. Oxford: Basil Blackwell, 1984: 81.

(4) Phillips D A. Religion without explanation. Oxford? Basil Blackwell, 1976: 21.

(5) Johnston P. Wittgenstein and moral philosophy. London and New York: Routledge, 1989.

(6) Sykes J B, ed. The concise Oxford dictionary [6th ed Oxford: Oxford University Press, 1976.

(7) See reference (1): 163-173.

(8) Wittgenstein L. On certainty. Oxford: Basil Blackwelhy 1979: $\$ 192$.

(9) Wittgenstein L. Philosophical investigations. Oxford Basil Blackwell, 1968: $₫ 485$.

(10) See reference (8): $₫ 205$.

(11) See reference (9): $\$ 217$.

(12) See reference (8): $\$ 204$.

(13) See reference (5): 80.

(14) See reference (8): $\$ 110$.

(15) See reference (8): $\$ 359$.

(16) See reference (9): $\$ 19, \$ 23$.

(17) See reference (9): 200.

(18) See reference (9): 226.

(19) See reference (9): $₫ 325$.

(20) Wittgenstein L. A lecture on ethics. Philosophic review 1965; 74: 3-12.

(21) See reference (5): 201

(22) See reference (5): 92-94.

(23) Drury M O'C. The danger of words. Londor $\overrightarrow{0}$ Routledge and Kegan Paul, 1973: xiv.

(24) Kripke S A. Wittgenstein on rules and private languege an elementary exposition. Oxford: Basil Black 1982.

(25) See reference (3): 83.

(26) See reference (3): 212

(27) See reference (3): 213

(28) See reference (3): 21.

(29) See reference (9): $₫ 206$.

(30) See reference (9): $\$ 109$.

(31) Wittgenstein L. Culture and value. Oxford: Basi Blackwell, 1980: 3.

(32) See reference (5): 202-203.

(33) See reference (5): 96.

(34) Rhees R. Some developments in Wittgenstein's view of ethics. Philosophical review 1965; 74: 17-26.

(35) See reference (31): 16.

(36) See reference (5): 205.

(37) See reference (5): 111 .

(38) See reference (8): $₫ 612$.

(39) See reference (5): 207.

(40) See reference (34): 25.

(41) See reference (5): 108.

(42) Drury M O'C. Some notes on conversations with Wittgenstein. In: Rhees $\mathrm{R}$, ed. Ludwig Wittgenstein personal recollections. Oxford: Basil Blackwell, $198 \underset{\text { 91-111. }}{ }$ 